\title{
Beyond Managerialism: Contributions of Humanistic and Critical Perspectives to Organizational Scholarship
}

\author{
Severin Hornung, Thomas Höge, Christine Unterrainer \\ University of Innsbruck / Institute of Psychology
}

\begin{abstract}
This conceptual contribution identifies and deconstructs ideological rifts in management and organizational scholarship. People-oriented humanistic and critical perspectives are distinguished from the explicitly or implicitly profit- and performance-oriented mainstream. Past, present, and future manifestations of ideological antagonisms are examined. Underlying organizational paradigms are conversely oriented towards social-emancipatory belief-systems and ideals versus economic-utilitarian logics and objectives. Emancipation aspires to overcome oppression and limiting conditions, pursued in projects of humanization, such as organizational democracy, human relations, work redesign, and personality development. Utilitarian approaches emphasize economic imperatives of profits and performance, inherent in projects of economic rationalization, such as scientific management, personnel selection, leadership, and high-performance work systems. Philosophical roots, historical developments, and properties of antagonistic paradigms are reviewed. Drawing on a current academic debate, their present configuration is analyzed along the dimensions of individualism, competition, and instrumentality. These building blocks of neoliberal ideology are contrasted with humanistic ideals of individuation, solidarity, and emancipation. Exemplary applications of resulting counter-models to contents and processes of organizational research are examined. The paradigm of critical management studies is discussed as an alternative frame of reference, aimed at challenging psychologically, socially, or ecologically destructive, dysfunctional, or limiting tendencies with regard to work-related interests, ideologies, institutions, and identities, based on principles of de-naturalization, reflexivity, and nonperformativity. Propositions are developed, how dialectically integrating humanistic and critical perspectives can contribute to exposing and overcoming blind spots, theoretical paradoxes, defensive biases, and hidden agendas as ideological constraints of mainstream management and organizational scholarship.
\end{abstract}

Keywords: antagonisms; critique; ideology; mainstream; paradigms 